\title{
Bartleby educador, reflexiones sobre el nihilismo
}

Ana María Valle Vázquez

Marco Antonio Jiménez García

Professores da Universidade Autônoma do México (UNAM)

\section{RESUMO}

Existem várias sentidos para o niilismo proposto por Nietzsche, inclusive falase dele no plural: "niilismos”. Aqui optamos por uma interpretação própria considerando o relato de Herman Melville Bartleby, o escrevente, como uma encarnação do niilismo. Trata-se de pensar a relação entre certas formas de niilismo e Bartleby, à luz e à sombra das reflexões que Deleuze faz de Nietzsche. Nossa hipótese é que Bartleby é uma expressão viva do niilismo e que isto constitui um elemento substancial do trabalho educativo. Dito de outro modo, educar é um ato essencialmente niilista.

Palavras-chave: Niilismo; negar; o nada.

\section{RESUMEN}

Hay diversos sentidos en torno al nihilismo propuesto por Nietzsche, incluso se habla de ello en plural: "nihilismos". Aquí hemos optado por una interpretación propia considerando el relato de Herman Melville Bartleby, el escribiente, como una encarnación del nihilismo. Se trata de pensar la posible relación entre ciertas formas de nihilismo y Bartleby, a la luz y la sombra de las reflexiones que Deleuze hace de Nietzsche. Nuestra hipótesis es que Bartleby es una viva expresión de nihilismo y que esto constituye un elemento sustancial del quehacer educativo. Dicho de otro modo, educar es un acto esencialmente nihilista.

Palavras-chave: nihilismo; negar; la nada. 
Lo que relato es la historia de los próximos dos siglos. Describo lo que viene, lo que ya no puede venir de otra manera: el advenimiento del nihilismo. Tal historia ya puede ser relatada hoy, porque la necesidad misma está actuando aquí. Tal futuro ya habla a través de un centenar de signos, tal destino se anuncia por todas partes [...] Toda nuestra cultura [...] se mueve desde hace ya largo tiempo, con una torturante tensión que crece de década en década, como hacia una catástrofe: inquieta, violenta, precipitada, como una corriente que busca el final, que ya no reflexiona, que tiene miedo a reflexionar.

Nietzsche

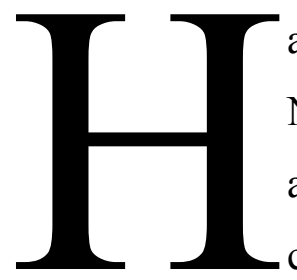

ay diversos sentidos en torno al nihilismo propuesto por Nietzsche, incluso se habla de ello en plural: "nihilismos", aquí hemos optado por una interpretación propia considerando el relato de Herman Melville Bartleby, el escribiente, como una encarnación del nihilismo. Se trata de pensar la posible relación entre ciertas formas de nihilismo y Bartleby, a la luz y la sombra de las reflexiones que Deleuze hace de Nietzsche. Nuestra hipótesis es que Bartleby es una viva expresión de nihilismo y que esto constituye un elemento sustancial del quehacer educativo. Dicho de otro modo, educar es un acto esencialmente nihilista.

¿Por qué recurrir a la concepción nihilista de Nietzsche para pensar la posibilidad de lo educativo? "Preferir no" puede ser el nihilismo de la voluntad de negar, así como el nihilismo del último hombre.

\section{Prefiero no}

Bartleby, el escribiente relata la historia de "un muchacho impasible, con figura pálida y pulcra, respetable hasta inspirar compasión, con un aire irremediable de desamparo" (MELVILLE, 2005, p. 20) quien acudió al llamado para trabajar con un abogado que tiene su oficina en Wall Street, New York. Él es quien relata su experiencia con Bartleby como escribiente de su despacho. El abogado dice de sí mismo:

[...] soy un hombre que desde su juventud, ha estado imbuido de una honda convicción de que la mejor forma de vida es la más sencilla. De ahí 
que, aunque mi oficio exija, en ocasiones, una energía y un nervio proverbiales, hasta rozar el desvarío, no haya permitido jamás que nada de esto turbe mi tranquilidad. Soy uno de esos abogados sin ambiciones que jamás se dirige a un jurado, ni hace por atraer el aplauso del público... En el fresco sosiego de un cómodo recogimiento, hago una labor cómoda entre obligaciones, hipotecas y títulos de propiedad de hombres ricos. Quienes me conocen me consideran, ante todo, un hombre seguro. (MELVILLE, 2005, p. 12)

Antes de la llegada de Bartleby al despacho, con el abogado colaboran tres empleados que por los apodos, que ellos mismos se habían asignado según sus respectivas personas y caracteres, se llamaban: Turkey (pavo), Nippers (tenazas) y Ginger Nut (nuez de jengibre). Turkey y Nippers son copistas o escribientes, en tanto que Ginger Nut es el chico de los recados. Turkey era un inglés bajito y regordete, más o menos de sesenta años, se consideraba la mano derecha del abogado, por la mañana no hacía más que desplegar sus fuerzas y por la tarde se ponía al frente de ellas, era descuidado al mojar la pluma en el tintero, por lo que sus copias estaban repletas de borrones (MELVILLE, 2005, p. 14-15). Nippers era un hombre patilludo, amarillo y con cierto aspecto de pirata, tenía unos veinticinco años y según el abogado era ambicioso, impaciente, irritable, indigesto y abstemio, no sabía lo que quería como escribiente o lo que quería no era otra cosa que verse libre de la mesa de escribiente (MELVILLE, 2005, p. 16-18). Ginger Nut, de apenas doce años, era un muchacho espabilado, para quien toda la noble ciencia del derecho cabía en una cáscara de nuez, entre sus deberes estaba el proveer de bizcochos y manzanas a Turkey y Nippers.

Ante su llegada, el abogado le asigna a Bartleby un lugar junto a la ventana. Al principio Bartleby realiza una gran cantidad de trabajo. Sin embargo, cuando el abogado (quien hace el relato) le solicita que examine con él un documento, Bartleby contesta: "Preferiría no hacerlo" ( I would prefer not to, en el original, que literalmente puede traducirse como “prefiero no"). "Su cara permanecía serena en su delgadez, el ojo gris oscuramente tranquilo. Ni la menor señal de turbación” (MELVILLE, 2005, p. 22). A partir de entonces, a cada requerimiento que se le hacía, Bartleby 
únicamente contestaría con esta contundente frase. Esta rara e inquietante negativa no le apartaba de seguir trabajando, aunque siempre estaba ajeno a todo lo que no fuese su propio trabajo. El abogado se da cuenta de que Bartleby no abandona nunca el despacho y que más bien, de manera clandestina, se ha quedado a vivir allí. Poco después, Bartleby decide no escribir más, por lo que es despedido, aunque evidentemente él no abandona el despacho, de tal manera que continua viviendo en la oficina. Incapaz de expulsarlo, y ante la clara incomodidad de los abogados que visitaban el despacho, el jefe del escribiente decide trasladar sus oficinas y dejar a Bartleby en Wall Street. Bartleby permanece primero en el despacho, luego al ser echado de ahí por el dueño deambula por el edificio hasta quedarse sentado en la barandilla de la escalera durante el día y en el zaguán por las noches. Finalmente es llevado a la cárcel, a lo que consintió con su impavidez y palidez características. Allí Bartleby, poco después de la última visita que le hace el abogado, se niega a comer y muere de hambre. El abogado lo encuentra "acurrucado de un modo extraño al pie del muro, las rodillas levantadas y echado de costado, la cabeza contra las frías piedras, sin el menor movimiento, sus ojos turbios estaban abiertos. Salvo por este detalle, parecía profundamente dormido" (MELVILLE, 2005, p. 54-55). Al final, en un breve y sorprendente epílogo, el abogado dice que según los rumores el antiguo trabajo de Bartleby, antes de llegar a su despacho, fue en la "Oficina de Cartas Muertas de Washington, de donde fue despedido por un cambio de administración" (MELVILLE, 2005, p. 56). Con sus mensajes de vida, estas cartas van directamente a la muerte. Así concluye Melville su extraordinario relato.

Bartleby es un texto de una violenta comicidad, dice Deleuze (2005, p. 59), donde lo cómico siempre es literal y lo violento se va desocultando a medida que avanza el texto. Podemos apreciar, a lo largo de todo el relato, dos mundos: el "normal", el de Wall Street, al que pertenecen el seguro, positivo y amable abogado, el descuidado Turkey y el impaciente Nippers. Por otro lado, el extraño mundo del inalterable Bartleby. El primero que dice sí "al correr de la vida", a las acciones permitidas, esperadas y asumidas por la comunidad. Y el segundo que "prefiere" decir "no" a esa vida y por ello 
muere.

"Prefiero no" es una elección negativa. No es que no se prefiera, que no se quiera, más bien lo que se prefiere es "no". Esta negativa, es lo que lleva al límite la preferencia. De esta manera la negación bloquea el querer externo, el querer de otro o el deseo ajeno para sólo quedarse con el más íntimo preferir de sí mismo. En otras palabras, lo que se niega es algo no preferido. Es una afirmación (preferir) que se niega (no) sólo para volverse a afirmar y volverse a negar. Cuando se afirma en la traducción que lo que se prefiere es "no hacerlo" algo queda explícito: "hacer". Lo que aquí sostenemos es que más allá del verbo "hacer", de la acción, de la palabra, incluso de los significados que pudiera tener el "hacer", lo que se prefiere es "no". Esto mismo vale cuando se confunde "nada" con "no", porque "preferir hacer nada" nunca es igual a "preferir no". Bartleby prefiere "no una voluntad de nada, sino la emergencia de una nada de voluntad" (DELEUZE, 2005, p. 63). Y justamente aquí está la intersección entre Bartleby y cierto nihilismo. A la nada de voluntad de Bartleby sólo le está permitido negar hasta la muerte. Su preferir no, su querer no, su desear no, es paradójicamente una voluntad de negar. Y la nada de voluntad es la oportunidad, el momento justo, de su muerte, es kairos tanathos, tiempo interior sin el cual la vida pierde sentido. No es el relato de la crónica de una muerte anunciada, sino de la muerte como coyuntura.

En esta extraordinaria intersección entre nihilismo y Bartleby, está la posibilidad de colocar a la educación en otro lugar, en el lugar de la voluntad de negar y en el de la nada de voluntad. Es decir, la educación como la facultad para "preferir no", la educación para bloquear la preferencia ajena, para no ceder al deseo del otro, la educación que prefiere negar la normalidad, la educación que mora en la imperturbabilidad de la extrañeza, la educación para preferir "no" antes que no preferir, la educación nihilista, aquella que permite al infante rechazar el castrante cuidado materno, aquella que permite al estudiante obturar la grotesca didáctica que ofusca. 


\section{Voluntad de negar y nada de voluntad}

Según Gonçal Mayos (1998a, p. 10) Nietzsche toma el nihilismo de Paul Bourget, quien lo concebía como la aparición y crecimiento de una "gran enfermedad europea, un mortal cansancio de vivir, una tétrica percepción de la vanidad de todo esfuerzo". Para el filósofo de Röcken (1998a, p. 171)

[...] No se ha comprendido lo que sin embargo es palpable: que el pesimismo no es un problema, sino un síntoma, -que este nombre tendría que ser substituido por el de nihilismo - que la cuestión de si el no-ser es mejor que el ser, es ya una enfermedad, un declinar, una idiosincrasia... el movimiento pesimista no es más que la expresión de una decadencia fisiológica.

Es decir, creer que el nihilismo como juicio es mejor que la realidad decadente, que el no-ser es mejor que el ser, es una enfermedad. Si la negación del ser es considerada mejor que la afirmación del ser, esto es una enfermedad, como menciona Nietzsche. La negación del ser, el nihilismo, es tan sólo un síntoma de la decadencia de la vida. El "preferir no" de Bartleby es un síntoma, no la enfermedad. Es la fiebre que anuncia un cáncer. Lo que está en descomposición es la vida misma y todo aquello que la afirma contribuye a esa patología. Como cuando el estudiante repite, sin ningún tipo de reflexión, lo que el profesor dice y en consecuencia el profesor aplaude la repetición de la afirmación. Es como saber que alguien está enfermo y fingir lo contrario. En todo caso se trata de no querer saber, para así poder afirmar la vida decadente. En el relato de Melville, el abogado y los escribientes afirman esa decadente vida plena de valores convencionales. La negación de Bartleby, de modo contradictorio, es el síntoma que está de parte de otra vida, es el nihilismo que niega la vida de los valores convencionales. Sin embargo, su imperturbable extrañeza hace patente la vida otra. Preferir no, es la negación del ser, es la voluntad de negar. Nos parece que Nietzsche apunta no sólo al anuncio del no-ser como enfermedad, antes bien a la negación de la decadencia de la vida. En otras 
palabras, lo que pareciera ser un pesimismo mortificante más bien es el contundente señalamiento y denuncia del ocaso de la vida encarnada en las bondadosas acciones del abogado de Wall Street. Esta negación de la declinación de la vida es tener la valentía para mirar el rostro de la Gorgona, no como suicidio sino como la asunción de lo inevitable, este sentido del nihilismo es una voluntad de negar. Bartleby es la monstruosa rareza insoportable de esta voluntad de negar, él con su "preferir no" detona la más profunda extrañeza de la afirmación (preferir) al negarla (no).

La tendencia hacia la "nada" no conduce a un vacío absoluto, este último sólo es posible en el pensamiento matemático o abstracto, aquí la nada es todo, que se nos presenta como caos inatrapable y originario, es el enloquecedor y mortífero canto de las sirenas. Educar en el reconocimiento de lo irreconocible, del caos, no significa desprenderse del cosmos, sino colocar la tensión entre el nihilismo, entre el "preferir no", y el sentido de la vida ascendente. No se trata de la vieja creencia de haber sido arrojados de un paraíso, el cual habría que restaurar, ni de inventar un paraíso al cual llegar. No es una metafísica que acaba de una vez y para siempre con lo viejo, descompuesto, putrefacto y perdido, para dar paso a lo nuevo, a lo sano, a lo limpio, a un súper hombre que reemplazaría al último hombre. Interpretar así a Bartleby es retornar a la serpiente que se muerde la cola, es renunciar a la experiencia humana demasiado humana.

¿Cómo interpretar la transmutación de los valores que hace el último hombre si no como una ironía revelada en el superhombre? ¿O acaso creer seriamente en esta figura es garantía de una vida sin enfermedad, mientras lo contrario, es decir, el dudar de la salvación es muestra, es síntoma, de estar enfermo? En otras palabras ¿creer en el superhombre, no como una ironía sino como una verdad, es señal de salud, de verdad y de salvación? O ¿mirar al superhombre como una ironía es un síntoma de una morbosa enfermedad? Parafraseando a Foucault, es mejor decir que: si antes fuimos objeto de salvación, mas no de verdad, hoy con seguridad somos objeto de verdad, mas no de salvación. Y aún esto último es sospechoso, todo parece indicar que las ideas de salvación y verdad están hoy día muy por debajo de la pretensión del valor "éxito". 
Quién se atrevería a proponer a un pesimista, a un nihilista como educador, cuando ser pedagogo, ser maestro, es sinónimo de un optimista hoy en día en las figuras de facilitador, instructor, animador, capacitador o promotor, que sin querer saberlo afirman la vida decadente. Bartleby deprecia al sistema. Con su voluntad de negar está próximo a una dialéctica negativa, a una lógica de la desintegración, a una deconstrucción radical de la vida, no se trata de un nihilista reactivo que responde contundentemente "no" a todo lo que se le demanda. Ya que no es el hombre que está cansado de querer (tiene voluntad de negar). En el hombre reactivo nada es verdad, nada está bien, Dios ha muerto. Ocurre la desvalorización de los propios valores, "la nada como voluntad no es sólo un síntoma para una voluntad de la nada, sino, en el límite, una negación de cualquier voluntad, un taedium vitae” (DELEUZE, 1998, p. 208). El nihilista reactivo niega la voluntad. Este sentido del nihilismo refiere a "...que los valores supremos pierden validez. Falta la meta; falta la respuesta al 'por qué' " (NIETZSCHE, 1996, p. 33). Bartleby no mata a Dios, no enaltece la ciencia, no niega las instituciones, no hace revolución, sencillamente "prefiere no". Y con esto produce una insoportable vorágine en la existencia de todos aquellos que le rodean al grado de expulsarlos del torbellino en el que él fenece. Quienes huyen del despacho son el abogado y sus empleados, por lo insoportable de la negación que evidencia Bartleby.

¿Qué es lo que mira Bartleby a través de la ventana cercana a su escritorio? La afirmación de la declinación de la vida, que él es el último hombre, la asunción de lo inevitable que es su muerte, en fin, la imposibilidad, el caos, la nada. Y es precisamente ahí donde Bartleby se muestra como maestro, es decir, cuando su nihilismo, su voluntad de negar, su ser síntoma, nos devela que es de la nada de donde proviene toda creación. Lo cual no quiere decir que esto es mejor, ascendente, progresivo o lineal. Yerran quienes confunden creación con lo bueno, lo bello, lo verdadero, lo útil, lo mejor o con lo sano, toda creación implica destrucción, maldad, fealdad, falsedad, inutilidad, corrupción y violencia. El reconocimiento de que todo acto pedagógico es una experiencia violenta no es algo extraordinario. 
El nihil, dice Deleuze (1998, p. 207), atendiendo a Nietzsche, "no significa el no-ser, sino un valor que es un valor de la nada [de todo]. La vida toma un valor de nada siempre que se la niega, se la deprecia." La vida de Bartleby tiene este valor de nada. En este estado del nihilismo, como voluntad de negar, lo que se niega es la vida decadente, lo que se niega es la vida como nada, lo que se niega es la vida donde hay valores superiores a ella misma. Cuando hay valores superiores a la vida es posible depreciarla. Se puede depreciar la vida, negarla, incluso aniquilarla, cuando por ejemplo los valores fabriles, como competencia, costo, utilidad, eficiencia o eficacia están por encima de la vida. Esta vida sobajada, esta vida subsumida, esta vida depreciada es la que se niega, es la que toma un valor de nada. No es que la vida no valga nada, sino que la vida vale "nada". Aquí la nada está colmada de sentido: el sentido de negar, el sentido de la posibilidad de "preferir no".

Educar permite vivir para morir consigo mismo sabiendo que es desde su propia carne que Bartleby niega, porque el cuerpo no se tiene sino que se es un cuerpo, es decir, "no tengo un cuerpo, soy mi cuerpo". Es la posibilidad de resistirse a las redes de la maquinaria del sistema educativo, que mortifica, que provoca una muerte estéril. Bartleby no es que no haga nada, sino que no hace. No es lo mismo no hacer nada que no hacer. Por ejemplo, un estudiante que "no hace nada" es aquel que en primera instancia cumple a la perfección y con éxito lo que la institución, el sistema, la sociedad, su familia y el maestro le demandan; también es aquel que no cumple por pereza, desidia, indiferencia o rebeldía hacia las mismas instancias. El estudiante que "no hace", aquel que "prefiere no", en principio es quien ha elegido algo propio, algo distinto de sí, es aquel que no ha cedido, por diversos caminos, a la demanda ni al deseo del otro, ni para bien ni para mal, es el que no pretende ser héroe ni antihéroe: "es lo que es". Lo cual, por lo regular, se tiene que pagar con un pedazo de carne del propio cuerpo.

No es que exista a priori o se pretenda la pureza de Bartleby, no se trata de santificar a Bartleby, sino de reconocer la posibilidad del nihilismo como voluntad de negar y como nada de voluntad. En este sentido la 
educación se establece en el "espíritu del don de nada" y no como una experiencia que considera a la enseñanza como un acto de amor, es decir, de dar lo que no se tiene a quien no corresponde, pensada así la educación estamos en un régimen de intercambio que sólo hace circular bienes materiales, útiles, conocimiento, información, datos para "el bien" de los otros.

Marcel Mauss (1979, p. 157) en su "Ensayo sobre los dones" se interroga: "¿Qué fuerza tiene la cosa que se da, que obliga al donatario a devolverla?”, en otras palabras, ¿cuál es el espíritu del Don? De acuerdo con él, lo que ata, lo que vincula, lo que re-liga y hace comunidad es "nada", que no es vacío, antes bien es todo aquello que no es útil, que no es comprable porque no es vendible, porque no es fabricable, que no es mercancía, que no es un artefacto. Lo que se intercambia bajo el principio de "el Don de nada" "no son exclusivamente bienes o riquezas, muebles e inmuebles, cosas útiles económicamente; son sobre todo gentilezas [...] en las que la circulación de riquezas es sólo uno de los términos de un contrato mucho más general y permanente" (MAUSS, 1979, p. 160). Gentilezas que pueden ser un guiño, una mirada, un bostezo, un gesto, una sonrisa, un ademán o una frase como: "prefiero no". Bartleby es un gentil negativo, que encarna el espíritu del don de nada.

Continua Deleuze (1998, p. 207), "la depreciación supone siempre una ficción: se falsea y se deprecia por ficción, se opone algo a la vida por ficción. La vida entera se convierte entonces en irreal, es representada como apariencia, toma en su conjunto un valor de nada". Esta ficción está representada en el melodrama de Wall Street actuado por el abogado, los empleados y demás personajes en derredor de Bartleby. Es un melodrama que se escenifica en torno a una tragedia.

Siguiendo a Nietzsche (1997, p. 39-40)

Ni la moral, ni la religión tienen contacto, en el cristianismo, con punto alguno de la realidad. Causas puramente imaginarias ("Dios", "alma", "yo," "la voluntad libre") [...] Este puro mundo de ficción se diferencia, con gran desventaja suya, del mundo de los sueños, por el hecho de que 
este último refleja la realidad, mientras que aquél, falsea, desvaloriza, niega la realidad. Una vez inventado el concepto naturaleza, como anticoncepto de "Dios", la palabra para decir "reprobable" tuvo que ser "natural", todo aquél mundo de ficción tiene su raíz en el odio a lo natural (-ila realidad!-) [...] Pero con esto queda aclarado todo ¿quién es el único que tiene motivos para evadirse, mediante una mentira, y de la realidad? El que sufre de ella. Pero sufrir de la realidad, significa ser una realidad fracasada... La preponderancia de los sentimientos de displacer sobre los de placer es la causa de aquella moral y de aquella religión ficticias: tal preponderancia ofrece, sin embargo, la fórmula de la décadence...

Sin duda reconocemos en Nietzsche dos formas de negar la realidad, de depreciarla: aquella que es representada por el Abogado y la que encarna Bartleby. La primera vive en un puro mundo de ficción, es un trato entre seres ficticios: Sistema, Burocracia, Instituciones, Ciencias, Dios, Gobierno, Curriculum Vitae, etcétera, esta realidad de ficción lo que niega es la vida, o la naturaleza, como dice Nietzsche. La de Bartleby niega esa realidad de ficción, es una postura radical, es la realidad del nihilismo; él vive en los márgenes con su soledad.

¿Qué no es la educación contemporánea un mundo de ficción? Para nosotros, la realidad ficticia no es la falsa, la mala ni la equívoca; ni tampoco la realidad de Bartleby, la natural, es la alternativa, la buena, la verdadera ni la salvadora. Todo lo contrario, Bartleby como educador, nos remite a la tensión constante entre la ficción, la decadencia, y lo que Nietzsche llama la vida natural, la realidad. Cualquier pedagogía que proponga un adelanto o un progreso a un mundo mejor está condenada al fracaso, a la mentira, a la más profunda decadencia.

La educación que Nietzsche nos propone es la del resentimiento, entendido éste como "volver a sentir", como no quedarse con la primera y más superficial sensación. Resentimiento que habla de que la vida es una vida sensible, no sólo razonable. Resentimiento en el reconocimiento del vínculo del don de la palabra entre maestro y alumno, en donde, parafraseando a Blanchot, "basta una palabra para destruirme, basta una palabra para salvarme". De ningún modo Bartleby es un resentido social que 
niega la vida, un reaccionario sin palabras, un mediocre o un charlatán. Pero tampoco un hombre de éxito, un diletante o con estatus social. Es, si se quiere, un residuo emblemático de lo que Nietzsche llama "el último hombre."

Bartleby al "preferir no" lo que prefiere es nada y no algo. El escribiente cancela la posibilidad de cualquier acción, de todo algo, digamos que da sentido a una imposibilidad, que es la negación misma. Es decir, esa pequeña acción de copiar, ese pequeño algo, ante el filo del "preferir no" se cancela y va anulando toda posibilidad, toda acción, todo algo; dejando sólo la imposibilidad, la pasividad, la nada. Prefiere, afirma, no hacer, no copiar, no responder, no llevar papeles, no cambiar nada, no decir, no comer. Hagamos un par de señalamientos: el primero es que desde el inicio lo que Bartleby "prefiere no" es "hacer", "preferiría no hacerlo" es tal cual se traduce I would prefer not to; lo que prefiere es no hacer cualquier cosa. El segundo señalamiento, es que al final, ya en la cárcel, Bartleby lo que prefiere es no cambiar nada, no decir y no comer, lo que prefiere es la inmovilidad, la mudez y la muerte. Lo interesante es que su "preferir no" en absoluto es debilidad, desdeño, pereza o indiferencia, sino todo lo contrario; es fuerza, respeto, energía y perseverancia. En este sentido Bartleby educador potencia esta fuerza, respeto, energía y perseverancia de la voluntad de negar como de la nada de voluntad. Una educación que afirma la negación de hacer algo, que afirma la inmovilidad, la mudez y la muerte no como suicidio ni como pesimismo mortificante, sino, como hemos dicho, en la asunción de lo inevitable y la negación de la decadencia de un tipo de vida. Bartleby es el último hombre, su muerte es la emergencia de una nada de voluntad. Para el "preferir no" es lo implícito de la acción, es el momento de la aparente ingenuidad.

En su libro La voluntad de poderio, Nietzsche (1996, p. 41) menciona un doble sentido del nihilismo: "[el] nihilismo como signo del creciente poder del espíritu: nihilismo activo. El nihilismo como decadencia y retroceso del poder del espíritu: nihilismo pasivo". El poder del espíritu se aleja de la ficción, se repliega ante la depreciación de la vida, es pasivo porque no cede al ideal ni a las esperanzas “vividas" por el resto del mundo. 
"El inicio de un crecimiento decisivo y completamente esencial, del paso a nuevas condiciones de existencia, sería que viniera al mundo la más extrema forma de pesimismo, el auténtico nihilismo" (NIETZSCHE, 1998, p. 87), este es el nihilismo del último hombre. Digamos que el auténtico nihilismo es aquel que habita el extremo de la asunción de lo inevitable, de la muerte. La muerte encarnada en el último hombre no es fatalismo, no es mordacidad corrosiva, más bien, es quien quiere la nada:

¡Llega el tiempo en que el hombre dejará de lanzar la flecha de su anhelo más allá del hombre, y en que la cuerda de su arco no sabrá vibrar! [...] Llega el tiempo del hombre más despreciable, el incapaz ya de despreciarse a sí mismo ¡Mirad! Yo os muestro el último hombre. ¿Qué es amor?, ¿Qué es creación? ¿Qué es anhelo? ¿Qué es estrella? así pregunta el último hombre, y parpadea. (NIETZSCHE, 1998-2, p. 38-39)

Efectivamente el último hombre es el que prefiere una nada de voluntad, apagarse pasivamente antes que una voluntad de la nada.

\section{Palabras finales}

Imaginemos por un momento que el despacho de abogados es un salón de clase donde el maestro es el Abogado. Lo que se enseña es ficción. El maestro pide a los estudiantes que colaboren en una tarea común y que trabajen en grupo; uno de ellos le responde "preferiría no hacerlo". El asombro del maestro es grande ¿qué quiere decir? ¿Se ha vuelto loco? El maestro insiste: hay que corregir en equipo la tarea, repasar la lección y revisar el escrito. $\mathrm{Y}$ el estudiante responde, con una mansedumbre, una tranquilidad, sin la menor turbación, sin malos modos o impertinencia: "prefiero no". El maestro se percata de que hay algo en ese estudiante fuera de lugar, extraño, irreconocible, anómalo y desconcertante. Por supuesto los demás compañeros están molestos porque éste se niega a colaborar en el trabajo común, incluso alguno de ellos le ofrece al profesor obligar a su compañero estudiante a cumplir con lo que la institución demanda. Sin 
embargo, el mentor no acepta, se queda perplejo y pensativo, porque efectivamente lo que este alumno negativo le devuelve no es sólo un "no" sino un conjunto de gentilezas, de gestos, de actitudes que hacen imposible considerarlo como un simple mediocre, flojo, rebelde e indiferente. Hay una voluntad en ese estudiante que al tiempo que perturba al colectivo se hace impenetrable e imperturbable. De ninguna manera por miedo, por maldad, por amor, por bondad, sino por rareza, él es algo a quien no se le teme pero tampoco se le tiene confianza, no se le odia ni se le ama. Se sabe que está vivo, que hace, aunque cada vez menos, pero que esa vida y ese hacer nada tienen que ver con la de los otros. Como si se tratase de un ser de "otro mundo" que anuncia otra cosa por venir.

Ahora supongamos que el maestro es Bartleby, lo que se enseña es el mundo "real" y "natural", esto es lo que nos anuncia, como la buena nueva. Anuncia con su vida el fin de una era y el principio de otra, es el último maestro. Que frente a la demanda institucional y social de enseñar, de educar o de instruir, él responde: "prefiero no". Y en esto radica su enseñanza. Los alumnos perplejos insisten a su maestro hacer algo, lo que sea, que les señale un camino; y el maestro sostiene sin perturbación alguna su respuesta: "prefiero no". Ante cada demanda social, cultural, de sus alumnos, la voluntad de negar del profesor es cada vez más fuerte. Frente a las preguntas e iniciativas de sus estudiantes por hacer algo, el maestro mira a través de la ventana "nada" y responde "prefiero no". Ante las afirmaciones formuladas como invitaciones a comer, a hablar y a trabajar de sus estudiantes, el maestro tranquilamente, con paciencia, con serenidad y con respetuosa distancia dice: "prefiero no". Ni siquiera le es necesario y posible dar las gracias. Los alumnos hartos de esta condición, abandonan el aula. Los burócratas escolares no saben qué hacer con el maestro que permanece deambulando en los pasillos, sin establecer contacto alguno con el personal. Deciden finalmente llevarlo a una institución psiquiátrica donde él se resiste a comer o a entablar cualquier lazo social para finalmente morir acurrucado en su propio cuerpo.

Bartleby es voluntad de nada (voluntad de negar la vida depreciada) al mismo tiempo que "prefiere una nada de voluntad [la muerte] apagarse 
pasivamente, antes que una voluntad de la nada" (DELEUZE, 1998, p. 244) El escribiente pasa por dos estados del nihilismo: el negativo y el pasivo. El primero que es la negación de la vida depreciada y el segundo que prefiere morir pasivamente antes que querer una voluntad de la nada. En un estado y en otro reina siempre el elemento de la negación como voluntad de poder, la voluntad como voluntad de la nada.

"El inicio de un crecimiento decisivo y completamente esencial, del paso a nuevas condiciones de existencia, sería que viniera al mundo la más extrema forma de pesimismo, el auténtico nihilismo" (NIETZSCHE, 1998, p. 87), esto es, que sólo a partir de la negación del valor y de la afirmación de la nada puede mutarse la esencia del ser humano, éste puede transvalorar los valores a partir de la nada y así pasar a algo diferente.

\section{Referencias consultadas}

DELEUZE, Gilles. Nietzsche y la filosofía. Anagrama: Barcelona, 1998, 275p. "Bartleby o la fórmula" p. 59-92. En Preferiría no hacerlo, 2005, Pretextos, Valencia.

NIETZSCHE, Friedrich. La voluntad de poderío. Edaf: Madrid, 1996, 555p. . El nibilismo: Escritos póstumos. Península: Barcelona, 1998a, 181p. . Así babló Zaratustra. Un libro para todos y para nadie. Alianza: Madrid, 1998b, 471p.

. El anticristo. Alianza: Madrid, 1997, 159p.

MELVILLE, Herman. Bartleby el escribiente. Pre-textos: Valencia, 2005, 192p.

MAUSS, Marcel. Sociología y Antropología. Tecnos: Madrid, 1979, 430p. 